\title{
Influence of structure on the compression behaviour of two very stiff fissured high plasticity Eocene clays
}

\author{
Kenny Kataoka Sorensen ${ }^{1, *}$ and Maryam Rezaei $^{1}$ \\ ${ }^{1}$ Aarhus University, Department of Engineering, 8000 Aarhus, Denmark
}

\begin{abstract}
A series of one-dimensional compression tests have been performed on reconstituted specimens of Søvind Marl. A clear correlation is obtained between the location and the gradient of the intrinsic compression lines and the void ratio at the liquid limit. The found correlation has subsequently been used to normalise the compression curves of 12 one-dimensional compression tests on intact specimens of Søvind Marl and Little Belt Clay obtained from various depths at two sites at Aarhus Harbour. Søvind Marl and Little Belt Clay are both marine sedimentary clays of Eocene age, which can be characterised as very stiff fissured clays with a very high plasticity. From a comparison of the reconstituted and intact compression paths the influence of structure is analysed and discussed in the paper. The majority of intact specimens of Søvind Marl and Little Belt Clay from Aarhus Harbour show similar behaviour; a very stiff recompression path and yielding at high stress level after crossing the intrinsic compression line. The displayed behaviour indicates an insignificant influence of fissuring on the pre-yield behaviour. Post-yield the compression paths indicate a stable structure dominated by fabric rather than metastable interparticle bonds. The paper furthermore highlights the importance of considering the effect of pore water salinity when assessing the influence of structure on the compression behaviour of smectite rich natural marine clays.
\end{abstract}

\section{Introduction}

The compression behaviour of natural sedimentary clays is strongly influenced by the micro- and meso-structure of the clay. Simplified the structure can be considered to consist of two components; fabric (arrangement of particles) and interparticle bonding. The structure developed during deposition of sedimentary clays is influenced by several factors, amongst others mineralogy, particle sizes and electrochemistry of the depositional environment [1]. On the other hand, post sedimentation structure can develop as a result of diagenesis and mechanical effects arising from e.g. erosion and glaciation events [2].

Several methods have been proposed to assess the effects of structure on the compression behaviour of natural clays, e.g. [2-4]. Common for all methods are that they relate the compression or swelling behaviour of the natural clay to the behaviour of the same clay in reconstituted state. Generally, it can be observed that natural stiff clays in compression will yield at higher stresses than found for the same clay in reconstituted state at a given void ratio, as a result of structure. After reaching yield, the compression curve of the natural clay will approach the normal (intrinsic) compression line (ICL) of the reconstituted clay if the clay experiences post-yield structural degradation, or it will stay parallel to the ICL, if the clay is characterised by a stable structure. However, some natural high plasticity stiff fissured clays tend to show gradual yield, and for these it can be very difficult to assess the yield stress [5] and effect of structure [4].

The intrinsic properties are primarily governed by mineralogy and grain size composition of the clay [3]. Furthermore, several studies have highlighted significant effects of pore water chemistry on the intrinsic properties of smectite rich clays e.g. [6-8]. This has however not received much attention in previous studies focusing on the effects of structure. Primarily due to the fact that the well-established framework for intrinsic behaviour and structured natural clays to large extend is developed based on clays with low content of smectite minerals [3,2].

Another challenge in making an accurate assessment of the effect of structure is to obtain two specimens of the same material; one intact and one reconstituted as reference. For some deep-water sedimentary clays of very high plasticity, such as the Danish Eocene clay Søvind Marl, significant spatial variations in mineralogy and carbonate content is found at $\mathrm{mm}$ scale. This makes it impossible in practise to obtain two identical samples from the same depth. Hence, if the intact specimen cannot be reused for creating the reconstituted counterpart, or if previously performed test on intact samples needs to be assessed, other methods need to be considered.

In this paper the effect of structure on the onedimensional (1D) compression behaviour of two very stiff sedimentary clays with high clay size fraction and smectite content is investigated. Data have been collected from commercial tests and literature on intact samples, and the results are compared to predicted intrinsic

\footnotetext{
*orresponding author: kks@eng.au.dk
} 
behaviour as established from supplementary tests on representative reconstituted soil samples.

\section{Site and soil description}

This study focuses on Søvind Marl and Little Belt Clay which have been extracted from three different sites at Aarhus Harbour, in the eastern part of Jutland, Denmark. Sites ZH, LH and HH are all located at Pier 4 within 100$300 \mathrm{~m}$. from each other. At Aarhus Harbour the upper soil strata consist of approx. 12 meters of sand fill with embedded layers of clay fill. The ground level is roughly $2.5 \mathrm{~m}$. above mean sea level (ASL) and the water table can be assumed close to $0 \mathrm{~m}$. ASL. Below the fill layer intact formations of Palaeogene clays are generally found. The clay formation is made up of Søvind Marl until approx. 72 meters depth, below which the older Little Belt Clay extend to more than $120 \mathrm{~m}$ depth [9].

Both Søvind Marl and Little Belt Clay are sedimentary clays deposited in a deep ocean during the Eocene period. The clays have a high clay fraction and are rich in smectite minerals resulting from volcanic activity in the North-East Atlantic at the onset of the Eocene period [10]. Subsequent significant sediment deposition followed by extensive erosion and successive glaciation events have led to the clays being heavily overconsolidated and very stiff and brittle in nature with typical peak undrained shear strengths greater than 300 $\mathrm{kPa}$ [9]. The highly fissured nature of the clays with randomly oriented fissures and the presence of slickensides is believed to be a result of stress relief and induced shear from glacial activity. [11] reported for Søvind Marl a clay fraction (CF) between 70 and $95 \%$ and a smectite content of $45-55 \%$ of the CF. The remainder of the clay size fraction is dominated by illite and kaolinite minerals approximately in equal quantities, and in some cases also calcite. Little Belt Clay have very similar CF and mineralogy. However, while the Little Belt Clay is almost non-calcareous, Søvind Marl has a varying content of calcite, typically around 5 to $65 \%[11,9]$. The pore water chemistry is found to be dominated by cloride ions, and at the LH site the cloride concentration was found to vary between roughly 5 to $15 \mathrm{~g} / \mathrm{L}[11,9]$. Similar pore water chemistry can be expected at the nearby sites.

Further information about the geology and geotechnical properties of Søvind Marl and Little Belt Clay can be found in $[11,10,12]$.

Table 1 lists the main characteristics of the tested reconstituted and intact samples. The two samples from site $\mathrm{LH}^{*}$ are from [11]. The sample nomenclature gives the sample state (r: reconstituted and i: intact) and the sampling depth in meters. The void ratio is generally determined from the initial water content and bulk unit weight of the sample. The specific gravity of solids is found to vary between $2.68-2.86$ with a mean value of 2.76 for the samples in the current study, assuming fully saturated samples. The liquid limit, $w_{L}$ for both intact and reconstituted clays is determined using the cone penetrometer method and mixing with demineralised water. The liquid limit for the tested soils ranges from 103 to $262 \%$, and the liquid limit generally tends to reduce with increasing calcite content. Søvind Marl and Little Belt Clay classifies as very high plasticity clays.

\section{Test methods}

Data from a large data base of commercial experimental tests conducted by the Danish company Geo have been used. Data have for this paper been extracted from 10 selected oedometer tests on intact specimens of Søvind Marl (5 no.) and Little Belt Clay (5 no.). In addition, two oedometer tests on Søvind Marl presented by [5] have been included and reanalysed. The test presented by [5] are also performed on samples taken from the test site LH, and they are included as they help to illustrate the compression behaviour at high stress levels. Only incrementally loaded oedometer test on specimens with liquid limits greater than $100 \%$ and compression to very high stress levels have been included in the current study.

Intact samples were tested in the conventional oedometer apparatus in either floating or fixed ring cells. Loading was applied incrementally from a stress level equal to the in-situ stress level to stress levels well inexcess of the preconsolidation pressure determined from geological loading history. The final stress level reached in each test ranged from $8000 \mathrm{kPa}$ to $22000 \mathrm{kPa}$. Specimens were either $35 \mathrm{~mm}$ or $60 \mathrm{~mm}$ in diameter, and the sample height was between 20 and $35 \mathrm{~mm}$. During sample preparation excessive drying of the samples may lead to opening of the natural fissures in the clay, which results in disturbance to the meso-structure. Hence, the time required for trimming the sample is generally sought minimized.

Four representative reconstituted samples of Søvind Marl were prepared by mixing thin trimmings of the intact clay with saline water to achieve a homogenous slurry with a water content of 1.25 times the liquid limit.

Table 1. Characteristics of tested reconstituted and intact samples

\begin{tabular}{|c|c|c|c|c|c|c|c|c|c|c|c|c|c|c|c|c|}
\hline $\begin{array}{l}\text { Sample } \\
\text { name }\end{array}$ & $\mathrm{i} 31$ & $\mathrm{i} 52$ & $\mathrm{i} 61$ & i74 & i80 & i95 & i105 & i121 & i29 & i39 & i13 & $\mathrm{i} 25$ & r6 & $\mathrm{r} 10$ & $\mathrm{r} 12$ & $\mathrm{r} 40$ \\
\hline $\begin{array}{l}\text { Soil type } \\
\text { (Site) }\end{array}$ & \multicolumn{3}{|c|}{$\begin{array}{c}\mathrm{SM} \\
\text { (LH) }\end{array}$} & \multicolumn{5}{|c|}{$\begin{array}{c}\mathrm{LB} \\
\text { (LH) }\end{array}$} & \multicolumn{2}{|c|}{$\begin{array}{c}\mathrm{SM} \\
\left(\mathrm{LH}^{*}\right)\end{array}$} & \multicolumn{2}{|c|}{$\begin{array}{c}\mathrm{SM} \\
(\mathrm{HH})\end{array}$} & \multicolumn{3}{|c|}{$\begin{array}{c}\mathrm{SM} \\
(\mathrm{ZH})\end{array}$} & $\begin{array}{c}\text { SM } \\
\text { (LH) }\end{array}$ \\
\hline$e_{0}[-]$ & 1.07 & 1.14 & 0.92 & 1.29 & 1.26 & 1.12 & 0.99 & 0.91 & $1.11^{\mathrm{a}}$ & $0.95^{\mathrm{a}}$ & 0.98 & 1.07 & 1.74 & 1.46 & 2.08 & 2.14 \\
\hline$w_{0}[\%]$ & 39 & 43 & 34 & 47 & 45 & 41 & 36 & 33 & 40 & 35 & 35 & 39 & 64 & 54 & 76 & 77 \\
\hline$w_{L}[\%]$ & 135 & 200 & 163 & 206 & 262 & 204 & 201 & 186 & $185^{\mathrm{b}}$ & $165^{\mathrm{b}}$ & 103 & 163 & 180 & 120 & 223 & 212 \\
\hline $\mathrm{CaCO}_{3}[\%]$ & 30 & 15 & 37 & 2 & 2 & 5 & 7 & 7 & 43 & 40 & 62 & 27 & - & - & - & - \\
\hline
\end{tabular}

Note: $e_{0}$, initial void ratio, $w_{0}$, initial water content, $w_{L}$, liquid limit, $\mathrm{CaCO}_{3}$, calcium carbonate content. ${ }^{a} e_{0}=w_{0} \cdot 2.75$ assumed,

${ }^{\mathrm{b}} w_{L}=I_{P} / 0.9+18$ assumed after [13] 
This process took several days. Saline water $2 \%$ (by mass) was made from tap water mixed with $\mathrm{NaCl}$. Subsequently, the reconstituted slurry was pre-consolidated to a nominal vertical stress of $150 \mathrm{kPa}$ in a $70 \mathrm{~mm}$ diameter floating ring consolidometer prior to being trimmed into cutting rings and transferred to the testing cell. Reconstituted specimens were like the intact specimens tested in the conventional oedometer apparatus. All specimens were tested in fixed ring oedometer cells and loaded incrementally to a vertical stress of $3200 \mathrm{kPa}$, with an intermediate unloading-reloading loop between $1600 \mathrm{kPa}$ and $100 \mathrm{kPa}$, and then final unloading to $10 \mathrm{kPa}$. Specimens were either $60 \mathrm{~mm}$ or $63.5 \mathrm{~mm}$ in diameter and $20 \mathrm{~mm}$ or $30 \mathrm{~mm}$ in height.

Saline water was used in the oedometer cell in all tests on reconstituted and intact specimens. Generally, it is expected that the differences in testing conditions for both intact and reconstituted specimens have limited influence on the results presented in the following sections.

\section{Intrinsic compression behaviour}

Figure 1 presents the compression curves of the four reconstituted specimens of Søvind Marl in a plot of end of consolidation void ratio, $e$ against vertical effective stress, $\sigma^{\prime}$. The reconstituted specimens represent high plasticity Søvind Marl with liquid limits spanning from $120 \%$ to $223 \%$. For specimen r10 the full compression curve including unloading-reloading is shown, while for the other specimens only the initial loading and virgin compression points are shown for clarity.

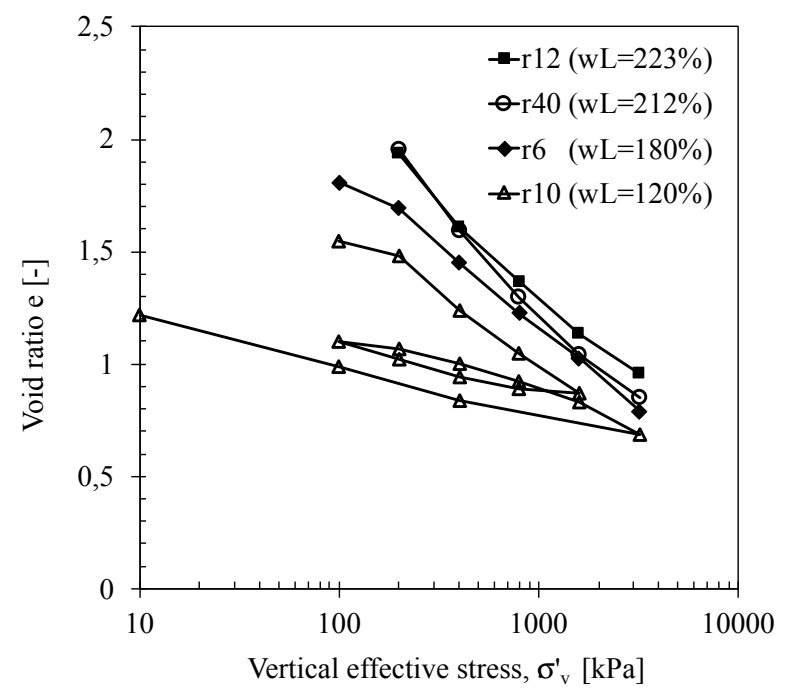

Fig. 1. Compression curves of reconstituted specimens.

For all four reconstituted specimens it is observed that the virgin compression points for each specimen after the initial load step and up to a vertical effective stress level of $3200 \mathrm{kPa}$ lie close around log linear lines. The best fit lines through the virgin compression points can be taken to represent the ICL's for Søvind Marl with the given liquid limits and stress intervals. The ICL is seen to shift upwards toward higher void ratios with increasing liquid limit of the specimen, while the gradient of the ICL on the other hand appears to be only little affected by variations in liquid limit.

The intrinsic constants of compressibility $e^{*} 100$ and $e^{*} 1000$ are defined as the void ratio on the ICL at the reference vertical stress of $100 \mathrm{kPa}$ and $1000 \mathrm{kPa}$ respectively [3]. In Figure $2, e^{*}{ }_{100}$ and $e^{*}{ }_{1000}$, extracted from the ICLs shown in Figure 1, are plotted against the void ratio at the liquid limit, $e_{L}$ for the tested specimens of Søvind Marl.

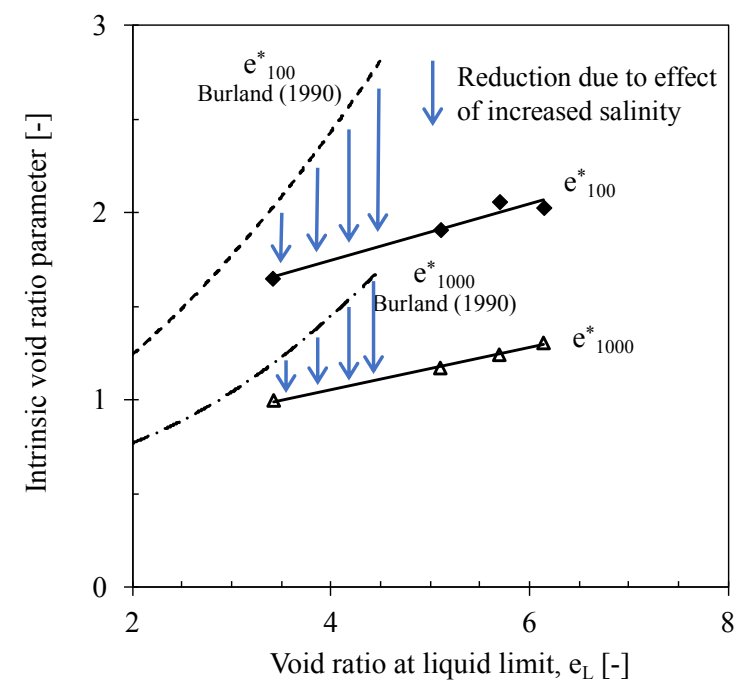

Fig. 2. Intrinsic constants of compressibility from tests on reconstituted Søvind Marl. Comparison with trendlines given by [3].

Both intrinsic constants of compressibility are found to increase approximately linearly with increasing void ratio at the liquid limit, and Equations 1 and 2 presents the relationships given by the best fit trendlines to the data points.

$$
\begin{aligned}
& e_{100}^{*}=0.153 \cdot e_{L}+0.113 \quad\left(R^{2}=0.95\right) \\
& e_{1000}^{*}=0.111 \cdot e_{L}+0.614 \quad\left(R^{2}=0.99\right)
\end{aligned}
$$

The intrinsic compression index $C_{C}^{*}=e_{1000}^{*}-e_{100}^{*}$ increases only slightly with increasing liquid limits, and values in the range 0.65 to 0.82 are found.

In Figure 2 the correlations given by [3] are also shown for comparison. These were derived based on compression tests on reconstituted natural clays with $e_{L}$ generally below $2.75\left(w_{L}<100 \%\right)$, however with a few very high plasticity clays (including Little Belt Clay from [14] with $\mathrm{e}_{L}$ up to around $4.5\left(w_{L}=159 \%\right)$. It is clear that the liquid limits of the clays included in this study far exceed those included by [3]. Furthermore, the data included in the study by [3] for high plasticity clays with $w_{L}$ above $100 \%$ has generally been obtained without consideration to pore water chemistry. Thus, the suggested trend lines shown in Figure 2 from [3] represent liquid limits and compression curves for reconstituted clays prepared with water with low or insignificant content of salt ions. Consequently, the natural salinities of the clays have been diluted and the intrinsic compression lines have been shifted upwards compared to what would have been obtained for reconstituted clays prepared using 
the natural pore water salinity (when plotted against void ratio at the liquid limit determined using demineralised water). An increasing effect of pore fluid salinity with increasing smectite content and hence increasing liquid limits would be expected as also indicated from Figure 2 for clays with $\mathrm{e}_{\mathrm{L}}$ greater than $2.75\left(w_{L}>100 \%\right)$.

As an example, the dilution of the pore fluid in reconstituted samples of Søvind Marl would be around 1:6 when considering a natural water content of around 40 $\%$ and the use of demineralised water to achieve a water content of $1.25 \cdot w_{L}$, with $w_{L} \sim 200 \%$. The corresponding reduction in pore fluid salinity would then be from around $1.5 \%$ in the intact sample to around $0.25 \%$ in the reconstituted sample. A reduction in this interval can be expected to have a very significant effect on the compression behaviour for smectite rich clays, as shown in the study by [6]. Recent result from [15] also indicate a similar reduction in $\mathrm{e}^{*}{ }_{100}$ and $\mathrm{e}^{*}{ }_{1000}$ in tests on Røsnæs clay with liquid limit around $125 \% \quad\left(e_{L} \sim 3.4\right)$ when reconstituted with saline water.

The compression behaviour of intact natural clays with liquid limits greater than $100 \%$ can be expected to show similar influence of pore water chemistry as seen in the study by [13]. Here the compression index of natural intact specimens of high plasticity heavily overconsolidated Palaeogene marine clays were found to be significantly lower than what could be predicted based on correlations with liquid limits found in the literature. This is a likely result of the influence of pore fluid salinity in the smectite rich clays.

Hence, when assessing the influence of structure on the compression behaviour, it is of utmost importance for smectite rich marine clays to create reconstituted specimens with the same pore water salinity as the intact clay, and a comparison should be made at the same liquid limit (determined with similar pore fluid).

\section{Influence of structure on the compression behaviour of intact clays}

Figure 3 and 4 shows the normalised ICL's and compression curves for intact specimens of Søvind Marl and Little Belt Clay respectively in plots of void index, $I_{v}$, as given by Equation 3 against the vertical effective stress.

$$
I_{v}=\frac{e-e_{100}^{*}}{e_{1000}^{*}-e_{100}^{*}}
$$

Where $e^{*}{ }_{100}$ and $e^{*}{ }_{1000}$ are determined from Equations 1 and 2 using the void ratio at liquid limit for the intact sample. The use of the void index as introduced by [3] effectively normalises the ICLs and intact compression curves for the influence of soil composition (mineralogy and grain size distribution), and as a result the individual ICLs are seen to define a more or less unique ICL.

From Figures 3 and 4 it is now possible to assess the influence of structure on the 1D compression behaviour of intact specimens of natural Søvind Marl and Little Belt clay included in this study. Despite significant differences in sample depth, calcite content and liquid limits the normalised compression paths of intact Søvind Marl in Figure 3 are seen to show quite similar behaviour. Only specimen 113 from the shallowest depth is seen to deviate, as it appears to display a stronger structure than seen for the other specimens. Generally, the initial recompression paths are very stiff and clearly crosses the ICL, thus showing a clear effect of structure. Though the compression paths show gradual yielding, points of gross yield, $\sigma_{y}^{\prime}$ are indicated on the log scale at stress levels around 5000 to $8000 \mathrm{kPa}$ after which the compression paths are indicated to run more or less parallel to the extended ICL. It should be noted that the extension of the ICL from a stress level of $3200 \mathrm{kPa}$ assuming a log linear continuation may not be strictly true, as the intrinsic compression line is likely to show slight curvature at high stresses/low void ratios. Furthermore, it should be noted that gross yield to some extend is an effect of plotting on a log scale, as yielding is not clearly observed when stress is plotted on a linear scale. Nevertheless, gross yielding at stresses greater than $4000-6000 \mathrm{kPa}$ is also indicated from the creep rates.

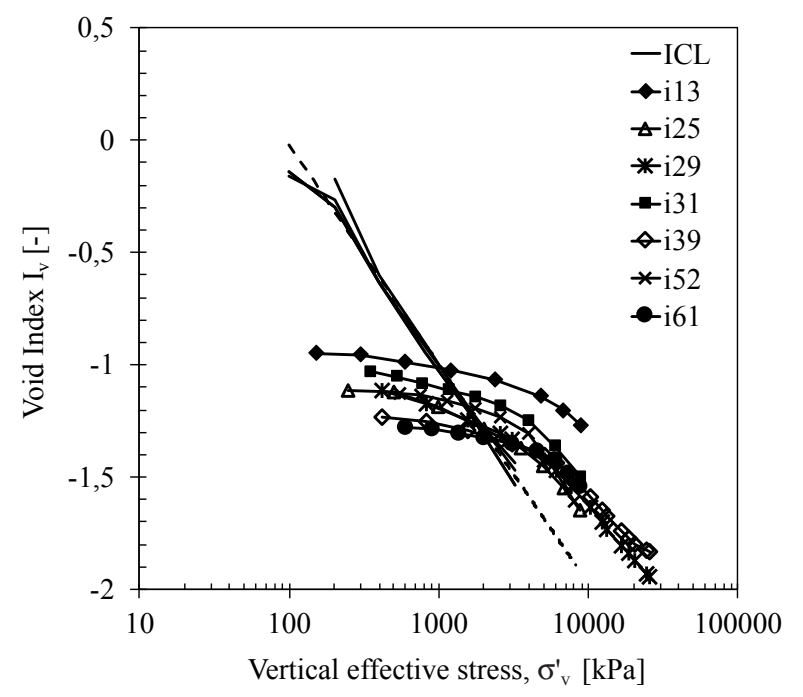

Fig. 3. Normalised compression curves of intact specimens of Søvind Marl. Comparison with ICL.

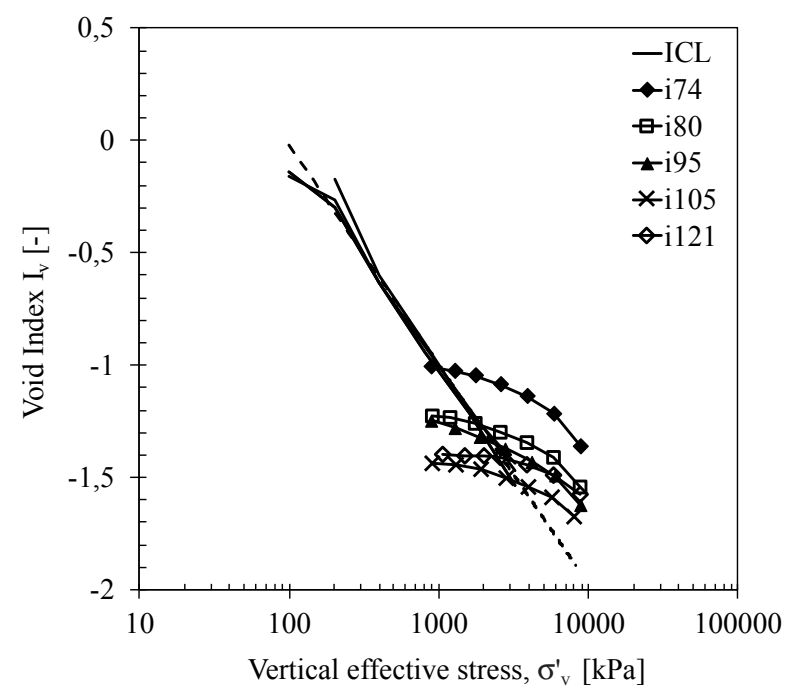

Fig. 4. Normalised compression curves of intact specimens of Little Belt clay. Comparison with ICL. 
It is generally expected to see a significant increase in the creep rates around yield [16]. In the test on intact specimens an increase above a rate of $0.5 \% / \log$ time is taken to indicate yield. Similar behaviour is indicated for intact specimens of Little Belt Clay from Figure 4. However, the post yield behaviour would be clearer had the specimens been compressed to higher stress levels.

An overview of the results from the 1D compression tests on both Søvind Marl and Little Belt Clay specimens is given in Table 3. The table lists values of in-situ stress, $\sigma_{0}^{\prime}$, yield stress $\sigma_{y}^{\prime}$, yield stress ratio, $Y S R=\sigma_{y}^{\prime} / \sigma_{0}^{\prime}$, post yield compression index, $C_{C}=\Delta e / \Delta \log \sigma_{v}^{\prime}$, and stress sensitivity ratio $S_{\sigma}=\sigma_{y}^{\prime} / \sigma_{e}^{\prime}$ defined by [17] as a measure of structure, where $\sigma_{e}^{\prime}$ is the equivalent pressure found on the ICL at the void ratio given by the yield point.

The magnitudes of $C_{C}$ for intact natural Søvind Marl and Little Belt Clat are found to be in the range 0.38 to 0.81 and 0.38 to 0.62 respectively. The values are in the same range, or slightly lower than the values determined from the tests on reconstituted Søvind Marl.

The stress sensitivity ratio $S_{\sigma}$ is found to be in range 2-2.8 (4.7 for specimen i13) for Søvind Marl, and in the range 1.7-2.5 (3.9 for specimen i74) for Little Belt Clay. $S_{\sigma}$ shows no trend with depth, however a weak trend of increasing stress sensitivity ratio with increasing calcite carbonate content is seen from Figure 5.

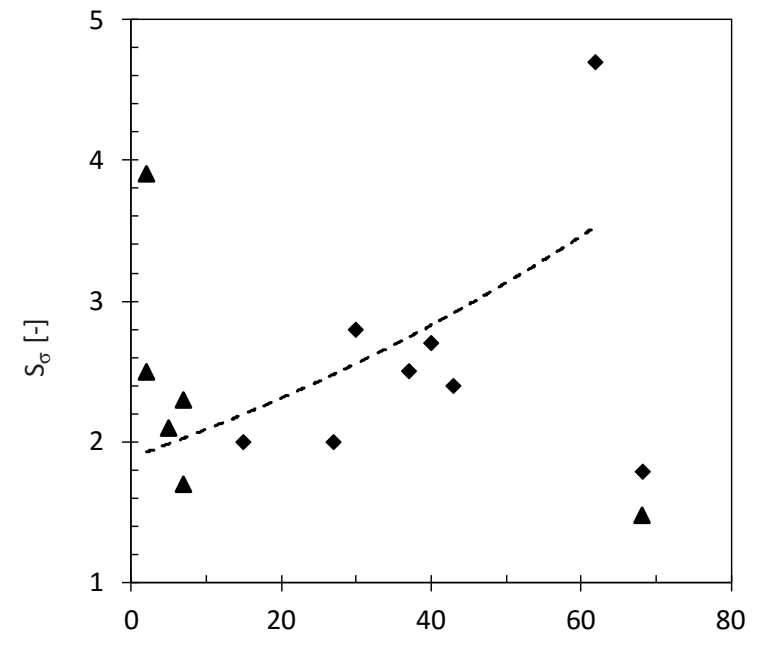

Fig. 5. Relationship between Stress Sensitivity Ratio, $S_{\sigma}$ and $\mathrm{CaCO}_{3}$ content for all specimens of Søvind Marl (SM) and Little Belt Clay (LB).
The high $\mathrm{CaCO}_{3}$ content of specimen i13 of Søvind Marl may therefore to some extend explain its apparent stronger structure. However, specimen i74 of Little Belt Clay, with an insignificant calcite carbonate content, stands out from this general trend, as it has a high $\mathrm{S}_{\sigma}$ value close to 4 . This does not seem to be only a result of high initial void ratio, as was suggested by [4], since the yield stress is comparable to that seen for the other specimens.

The observed behaviour for Søvind Marl and Little Belt Clay can generally be said to characterise soils with a stable structure dominated by fabric rather than a metastable bonding. Comparable behaviour was reported for fissured London Clay [4]. Hence, despite the fissured nature of Eocene clays such a Søvind Marl, Little Belt Clay and London Clay, the fissures do not appear to dominate the pre-yield behaviour, and also are not linked to a significant degradation of the structure at pressures beyond gross-yield. This is clearly in contrast to the strong influence of fissuring on the shear strength, as observed e.g. in triaxial compression of London Clay [18], and the high influence of intense fissuring on the pre-yield compression behaviour observed in oedometer tests on intensely fissured scaly clays and fissured bentonite [19].

It is believed that the explanation should be found in the micro- and meso-structure of the very stiff Eocene very high plasticity clays. Although fissured, these clays are typically characterised by a strong inter-fissure intact structure. In shearing (e.g. triaxial compression) the fissures will dominate the macro behaviour with strains concentrating along the weak planes. Whilst in 1D compression the fissures will remain closed or gradually close with increasing stress levels, and the behaviour will to a much higher degree be dominated by the intact interfissure structure, where strains are more globally distributed. Hence, the observed gradual yield in 1D compression of overconsolidated smectite rich clay specimens is believed to be controlled primarily by the physio-chemical properties of the smectite minerals and to lesser extend the presence of fissures.

\section{Assessment of yield pressure}

Several researchers e.g. [4-5] have highlighted and discussed the difficulties in assessing the yield pressure for firm fissured high plasticity clays.

Table 2. Result from 1D compression tests on intact samples

\begin{tabular}{|c|c|c|c|c|c|c|c|c|c|c|c|c|}
\hline Sample name & $\mathrm{i} 31$ & i52 & i61 & i74 & i80 & i95 & i105 & i121 & i29 & i39 & i13 & i25 \\
\hline Soil type (Site) & \multicolumn{3}{|c|}{$\mathrm{SM}(\mathrm{LH})$} & \multicolumn{5}{|c|}{$\mathrm{LB}(\mathrm{LH})$} & \multicolumn{2}{|c|}{$\mathrm{SM}\left(\mathrm{LH}^{*}\right)$} & \multicolumn{2}{|c|}{$\overline{\mathrm{SM}(\mathrm{HH})}$} \\
\hline$\sigma_{v}^{\prime}[\mathrm{kPa}]$ & 152 & 311 & 384 & 482 & 527 & 643 & 714 & 834 & 255 & 335 & 140 & 230 \\
\hline$\sigma_{y}^{\prime}[\mathrm{kPa}]$ & $\sim 5000$ & $\sim 5000$ & $\sim 7000$ & $\sim 7000$ & $\sim 7000$ & $\sim 7000$ & $\sim 7000$ & $\sim 8000$ & $\sim 7000$ & $\sim 8000$ & $\sim 8000$ & $\sim 6000$ \\
\hline YSR [-] & 33 & 16 & 18 & 15 & 13 & 11 & 10 & 10 & 27 & 24 & 57 & 26 \\
\hline$S_{\sigma}[-]$ & 2.8 & 2.0 & 2.5 & 3.9 & 2.5 & 2.1 & $\begin{array}{ll}\sim 7 \\
\sim\end{array}$ & $\begin{array}{l}2.3 \\
\end{array}$ & 2.4 & 2.7 & 4.7 & 2.0 \\
\hline$C_{C}[-]$ & 0.55 & 0.81 & 0.58 & 0.61 & 0.63 & 0.59 & 0.43 & 0.38 & 0.52 & 0.50 & 0.38 & 0.60 \\
\hline
\end{tabular}

Note: $\sigma_{v 0}^{\prime}$, vertical effective stress, $\sigma_{y}^{\prime}$, yield stress, $Y S R$, Yield Stress Ratio, $S_{\sigma}$, Stress Sensitivity Ratio, $C_{C}$, compression index 
These clays are typically observed to show gradual yield with no distinct yield point. Standard interpretation methods to assess the yield pressure are based solely on the observed compression or creep behaviour of the intact soil e.g. [20] [21] [16]. Typically, no consideration is made towards the limiting behaviour, which is determined by the intrinsic properties of the soil.

Knowledge of the intrinsic compression behaviour in relation to the intact compression behaviour will further assist in the assessment of the yield pressure, as can be seen from Figures 3 and 4 . At the yield point the gradient of the intact compression path changes and is found to become similar to that of the same clay in its reconstituted state at the same void ratio. Figure 6 shows the ratio of the intrinsic compression index $C_{C}^{*}$ to the gradient of the intact compression curve $C_{C}$ plotted against mean vertical effective stress on a log scale from three selected tests on Søvind Marl. The other test show similar results.

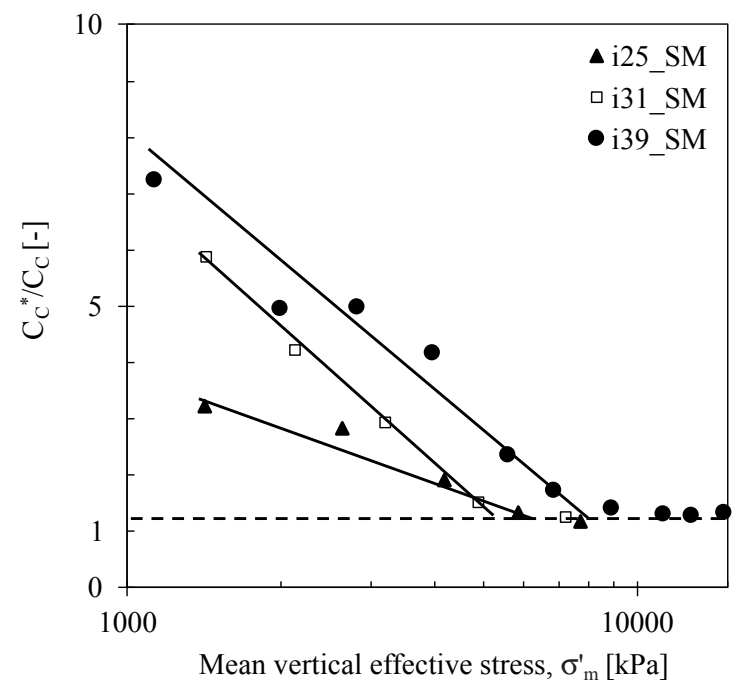

Fig. 6. Estimation of yield stress based on $\mathrm{C}{ }^{*} / \mathrm{C}_{\mathrm{C}}$ for three selected specimens of Søvind Marl.

Towards yield, as the value of $\mathrm{C}_{\mathrm{C}}{ }^{*} / \mathrm{C}_{\mathrm{C}}$ is approaching unity, an approximately linear relationship between $\mathrm{C}_{\mathrm{C}}{ }^{*} / \mathrm{C}_{\mathrm{C}}$ and $\log \sigma_{\mathrm{m}}^{\prime}$ is seen. For clays with a stable structure the value of $\mathrm{C}_{\mathrm{C}}{ }^{*} / \mathrm{C}_{\mathrm{C}}$ will remain constant after yield. The yield stress can now be taken as the intersection between the straight-line portion of the data points preyield and the horizontal line at $\mathrm{C}_{\mathrm{C}}{ }^{*} / \mathrm{C}_{\mathrm{C}}=1$. Values of yield stress determined using this method are given in Table 3. The yield stresses are found to lie in the range $5000 \mathrm{kPa}$ to $8000 \mathrm{kPa}$ with no clear trend with depth as could perhaps be expected. Corresponding yield stress ratios varies from a maximum of 57 at $13 \mathrm{~m}$. depth to around 10 at $105 \mathrm{~m}$. depth. The obtained values of yield stress are in fairly good agreement with the upper bound values determined by [5] for specimens of Søvind Marl at Aarhus Harbour.

\section{Conclusions}

This paper has shown how it is possible to assess the effect of structure on the compression behaviour of Søvind Marl and Little Belt Clay using the predicted intrinsic behaviour at a given liquid limit as a reference. The importance of considering the influence of pore water chemistry is highlighted from the test results. It is observed that the majority of intact specimens of Søvind Marl and Little Belt Clay from Aarhus Harbour show similar behaviour; a very stiff recompression path and yielding at high stress level after crossing the intrinsic compression line. The displayed behaviour indicates an insignificant influence of fissuring on the pre-yield behaviour. Post-yield, the compression paths are indicated to run parallel to the ICL indicating a stable structure dominated by fabric rather than metastable interparticle bonds.

Further testing should be carried out to verify the results and the proposed methods for a greater range of liquid limits and different soil types.

Geo is acknowledged for giving access to the database of results of oedometer tests on intact samples.

\section{References}

1. J.K. Mitchell,K. Soga (2005) Fundamentals of Soil Behavior. John Wiley \& Sons

2. F. Cotecchia, R.J. Chandler, Géotechnique, 47, 523 (1997)

3. J.B. Burland, Géotechnique, 40, 329 (1990)

4. A. Gasparre, M.R. Coop, Can. Geotech. J., 45, 1324 (2008)

5. G.L. Grønbech, L.B. Ibsen, B.N. Nielsen, Geot. Test. J., 38, 1 (2015)

6. C.D. Maio, L. Santoli, P. Schiavone, Mech. of mat., 36, 435 (2004)

7. B. Tiwari, B. Ajmera, Env. Geot., 1, 108 (2014)

8. Y. Yukselen-Aksoy, A. Kaya, A.H. Ören, Eng. Geol., 102, 54 (2008)

9. Geo (2015) Aarhus Havn. Pier 4, Byggefelt X2, Geotechnical soil Investigation - Data report.

10. C. Heilmann-Clausen, O.B. Nielsen, F. Gersner, Bul. of the Geol. Soc. of Denmark, 33, 287 (1984)

11. G.L. Grønbech, B.N. Nielsen, L.B. Ibsen,P. Stockmarr, Can. Geot. J., 52, 469 (2015)

12. C. Heilmann-Clausen, O.B. Nielsen, F. Gersner, Bul. of the Geol. Soc. of Denmark, 33, 287 (1984)

13. K.K. Sørensen, Proc. $67^{\text {th }}$ Can. Geotech. C. (2014)

14. K.K. Sørensen, N. Okkels, Proc. $16^{\text {th }}$ ECSMGE, 3371 (2015)

15. M.J. Hvorslev, Ingeniorvidenskabelige Skrifter, A (1937)

16. I.D.R. Rocchi, G.; Grønbech, G. L.; Zania, V., micro to MACRO Math. Mod. in Soil Mech. (2018)

17. K. Akai Die strukturellen Eigenschaften von Schluff. der Technischen Hochschule Aachen, 22 (1960)

18. F. Cotecchia, R.J. Chandler, Geotechnique, 50, 431 (2000)

19. A. Gasparre, S. Nishimura, M.R. Coop, R.J. Jardine, Géotechnique, 57, 19 (2007)

20. C. Vitone, F. Cotecchia, Géotechnique, 61, 1003 (2011)

21. A. Casagrande, Proc. $1^{\text {st }}$ ICSMFE, 3, 60 (1936)

22. N. Janbu, Proc. $7^{\text {th }}$ ICSMFE, 1, 191 (1969) 